${ }^{1}$ Chair and Department of Internal Diseases and Diabetology, Warsaw Medical University, Warsaw

${ }^{2}$ Department of Clinical Immunology, Institute of Transplantology, Warsaw Medical University, Warsaw

${ }^{3}$ Department of General and Vascular Surgery, Warsaw Medical University, Warsaw

\title{
The levels of interleukin-2 and interleukin-10 in patients with type 2 diabetes and colon cancer
}

\section{ABSTRACT}

Introduction. The risk of colon cancer (CC) development is increased significantly among patients with type 2 diabetes (T2DM). A mechanism responsible for a higher prevalence of CC among diabetic patients may be associated with disturbances of the immune system. Cytokines - interleukin-2 (IL-2) and interleukin-10 (IL-10) play relevant role in the immune response. The aim of this study was to investigate the differences in the immunological state in terms of IL-2 and IL-10 levels among groups of patients with T2DM, patients with CC, patients with T2DM and CC and patients without these diseases.

Material and methods. 80 patients were included in the tests and split into 4 groups: group $1-24$ patients with T2DM, group $2-24$ patients with CC, group 3 -10 patients with $C$ and T2DM, and group $4-22$ persons without T2DM or CC. Colonoscopy was performed for all the patients. All cases of colon cancer were confirmed by histopathological examination. Laboratory measurements included blood tests such as fasting glucose, insulin, $\mathrm{C}$-peptide and $\mathrm{HbA}_{1 \mathrm{c}}$. The serum concentration of IL-2 and IL-10 was determined by the immunoenzymatic (ELISA) method.

Address for correspondence:

prof. dr hab. n. med. Paweł Piątkiewicz

Katedra i Klinika Chorób Wewnętrznych, Diabetologii i Endokrynologii Warszawski Uniwersytet Medyczny

ul. Kondratowicza 8, 03-242 Warszawa

Phone/fax:+48223265817

e-mail: piatkiewicz@op.pl

Clinical Diabetology 2018, 7, 2, 114-121

DOI: $10.5603 /$ DK.2018.0006

Received: 01.12.2017

Accepted: 29.01.2018
Results. The concentration of IL-2 was statistically higher in the group of patients with T2DM and CC than in the groups of patients without those diseases $(4.21 \pm 1.61 \mathrm{SE} \mathrm{pg} / \mathrm{ml}$ vs. group $1-1.57 \pm 0.44 \mathrm{SE} \mathrm{pg} /$ $/ \mathrm{ml}$, group $2-1.64 \pm 0.27 \mathrm{SE} \mathrm{pg} / \mathrm{ml}$, group $4-1.95$ $\pm 0.47 \mathrm{SE} \mathrm{pg} / \mathrm{ml} ; \mathrm{p}<0.05)$. There were no statistically significant differences in the concentrations of IL-10 in patients with T2DM and CC compared with other subjects. The level of fasting glucose and $\mathrm{HbA}_{1 \mathrm{c}}$ in the groups of patients with T2DM (group 1) and T2DM with CC (group 3) was statistically higher than in the groups of patients without T2DM. There were no statistically significant differences between the groups in levels of insulin, C-peptide and HOMA-IR.

Conclusions. The concentration of IL-2 was statistically higher in the group of patients with T2DM and colon cancer than in other groups. Elevated level of IL-2 can be a marker of an increased risk of CC in people with type 2 diabetes. It might be useful in indicating a group of patients with differences in immune system particularly susceptible to the development of colon cancer. (Clin Diabetol 2018; 7, 2: 114-121)

Key words: type 2 diabetes, colon cancer, interleukin-2, interleukin-10

\section{Introduction}

Colon cancer (CC) is one of the most common malignancies worldwide. It is the third most common cancer in both sexes, and the second reason for cancer related deaths in the world [1, 2]. The high prevalence of CC among diabetic patients was confirmed in numer- 
ous epidemiological studies [3-5]. In Poland the number of patients suffering from type 2 diabetes (T2DM) exceeded 3 million. It is estimated that this group includes approximately $25 \%$ patients with undiagnosed diabetes [6]. A relevant mechanism which can affect the occurrence of cancer among diabetic patients is a disturbed function of the immune system. Interleukins play a crucial role in the immune response. Interleukins - IL-1, IL-2, IL-6, IL-10, IL-17, IL-35 may be involved in the development and proliferation of CC [7-13].

Interleukin- $\beta$ (IL- $1 \beta$ ) is secreted by immune, stromal and tumor cells. Elevated IL- $1 \beta$ level is associated with increased colon cancer growth and invasion [7].

Interleukin-2 (IL-2) exerts the influence on differentiation, proliferation and activity of lymphocytes. It is a crucial factor increasing proliferation of $\mathrm{T}$ regulatory (Treg) lymphocytes. The increased number of Treg lymphocytes in a colon tumor was associated with the progression of cancer and higher prevalence of metastases $[8,9]$.

IL-2 is produced mainly by CD4+ Thelper (Th) cells in secondary lymphoid organs (e.g. lymph nodes) and by $\mathrm{CD} 8+\mathrm{T}$ cells, natural killer (NK) cells and natural killer T (NKT) cells. IL-2 can be also secreted by activated dendritic cells (DCs) and mast cells [14].

IL-2 production by CD4+ and CD8 $+\mathrm{T}$ cells is induced by antigen. IL-2 production is regulated among others by the transcription factor - B lymphocyteinducing maturation protein 1 (BLIMP1) which inhibits IL-2 synthesis. On the other hand, IL-2 activates BLIMP1. The cells with low expression of BLIMP1 can produce IL-2 in a large amount. A prolonged stimulation of T cell receptor (TCR) by antigens leads to the upregulation of BLIMP1 and diminishing of IL-2 production [15, 16].

The main action of IL-2 includes the stimulation of Treg lymphocytes proliferation, T cytotoxic lymphocytes activation, cytolytic capacity augmentation of NK cells, $B$ lymphocytes proliferation and inhibition of Th17 lymphocytes differentiation. Treg cells can regulate CD8+ T cell responses by limiting IL-2 production, reducing the number of CD8 $+\mathrm{T}$ cells and stimulation of generation memory T cell. IL-2 stimulation of Treg lymphocytes proliferation may be responsible for the development of cancer antigen tolerance [17].

Interleukin-6 (IL-6) is a tumor promoting factor in colorectal cancer. Elevated level of IL- 6 was observed in patients with $\mathrm{CC}$, both in the serum and tumor tissue. IL-6 is produced by monocyte, macrophages, fibroblasts, $B$ cells, T cells and also by tumor cells. In chronic inflammation T cells are the significant source of IL-6 [10].

Interleukin-10 (IL-10) plays an important role in inflammation, allergy and cancer development. The major sources of IL-10 are T lymphocytes CD4+ (Th1, Th2, T reg, Th17). IL-10 may be also secreted by CD8+
T cells, monocytes, macrophages, subsets of dendritic cells (DCs), B cells, eosinophils, mast cells [11].

The non-immune cell sources of IL-10 include keratinocytes, epithelial cells, and even tumor cells. A necessary condition of IL-10 production by T cells is their activation by antigen presenting cells $[11,18,19]$.

IL-10 has an anti-inflammatory activity. IL-10 inhibits the production of proinflammatory cytokines e.g. IL-1, IL-6, IL-12, and tumor necrosis factor (TNF). IL-10 can also stimulate B-cell activation and can prolong B-cell survival. IL-10 increases the availability of tumor associated antigens (TAAs) by stimulating NK cells responsible for the cytolysis of tumor cells. On the other hand, IL-10 acting on dendritic cells may be responsible for $\mathrm{CD} 8+\mathrm{T}$ lymphocyte anergy against TAAs $[18,20]$.

The progression of CC may be associated with an increase of IL-10 serum levels. A poor survival rate was shown among patients with high preoperative serum levels of IL-10 and colorectal cancer. It may suggest a tumor-promoting role of IL-10 in patients with CC. The progression of CC may be also associated with the change of cytokine production by Treg cells from IL-10 to IL-17. IL-10 binding to its receptor activates STAT1, STAT3 and STAT5. The role of IL-10 in the development and progression of CC is complex and can be associated with immune system suppression or stimulation $[11,21,22]$.

Interleukin-17 (IL-17) is a proinflammatory cytokine and a tumor promoting factor in case of colon cancer. IL-17 is secreted by different cells among others T cells (predominantly Th17 cells), NK cells, neutrophils [12].

Interleukin-35 (IL-35) is an anty-inflammatory cytokine. As demonstrated in the Chinese study IL-35 may have an inhibitory effect on colon cancer progression [13].

There is a need of further assessment of interleukin impact on colon cancer development.

\section{Aim of the study}

The aim of the study was to demonstrate the differences in the immune system in terms of the cytokines concentration - IL-2 and IL-10 in the groups of patients with T2DM and concomitant CC compared to patients with CC without T2DM, patients with T2DM without CC and patients without T2DM and CC. Studies have been conducted to identify possible relationships between the levels of IL-2 and IL-10 and the risk of development of CC in patients with T2DM.

\section{Material and methods}

This study was performed in the Chair and Department of Internal Diseases and Diabetology and the 
Department of General and Vascular Surgery, Medical University of Warsaw, and the Clinic of Metabolic Diseases and Gastroenterology Institute of Food and Nutrition in Warsaw. This study was approved by the local Research Ethics Committee and conducted in accordance with the Helsinki Declaration. Informed written consents were obtained from all the participants. They were informed about the rules for their safety. Each patient was included in the study after obtaining their informed written consents.

Participants authorized for individual groups were subjected to the internal study with a detailed account of the interviews collected in the form of data survey on demographic, environmental, clinical and family history. Qualifying tests were conducted under the protocol approved by the Commission of Bioethics at the Medical University of Warsaw. Colonoscopy was performed among all the patients participating in the study. All cases of colon cancer were confirmed by histopathological examination. In the case of cancer, computed tomography (CT) was performed. The patients with inflammatory bowel disease were not included into the study.

The study involved 80 patients who were divided into 4 groups: group 1 (24 patients) with T2DM, group 2 (24 patients) with CC, group 3 (10 patients) with T2DM and CC, and group 4 (22 persons) without T2DM and cancer. Exclusion criteria included previous cancer history, systemic corticotherapy, pregnancy, lactation, acute infections, drug and alcohol addiction. Also the patients with renal insufficiency with creatinine above 2 $\mathrm{mg} / \mathrm{dl}$ and transaminase levels above 3 times the upper limit of normal range were excluded from the study.

Laboratory measurements were performed in the research laboratory of the Department of Internal Diseases and Diabetology, Warsaw Medical University, and in the Masovian Bródnowski Hospital laboratory in Warsaw. Laboratory studies included the following examinations: fasting plasma glucose (FPG) in the plasma of venous blood by enzymatic method implemented with glucose oxidase and marking of $\mathrm{H} 2 \mathrm{O} 2$, insulin and C-peptide by radioimmunologic method. The HOMA-IR (homeostatic model assessment-insulin resistance) was calculated by the following formula concentration of fasting insulin $(\mathrm{mU} / \mathrm{l}) \times$ fasting glucose level $(\mathrm{mmol} / \mathrm{l}) / 22.5$.

Identification of the IL-2 occurred at the Department of Clinical Immunology, Institute of Transplantology of Warsaw Medical University. $5 \mathrm{ml}$ of peripheral blood from the cubital vein were taken for the test tubes without anticoagulants. Then the blood was centrifugated at a speed of $2000 \mathrm{rpm}$ for 10 minutes. The obtained supernatant was portioned in properly marked containers and then frozen $\left(-70^{\circ} \mathrm{C}\right)$. The concentration of IL-2 was analyzed by the immunoenzymatic ELISA method with ready-to-use jet kits Human IL-2 ELISA (DIACLONE Research, France) in binary reps. The concentration of IL-10 was analyzed by the immunoenzymatic ELISA method with ready-to-use jet kits Human IL-10 ELISA (DIACLONE Research, France) in binary reps.

For comparison of the studied groups, the statistical parameters characterizing the variability of the evaluated features were calculated. Basic statistical parameters characterizing the variability of the evaluated features such as average, standard deviation, standard error and median were calculated for each group. In order to compare the significances of differences between averages, a single agent analysis was conducted and groups were created using the Fisher method. Comparing the groups in terms of gender percentages was carried out using the $\chi^{2}$ test of independence. We used $p$ value to determine statistical significance. The assumed level of statistical significance was 0.05 . Analyses were performed using the statistical program Statistica 10 (StatSoft)

\section{Results}

There were no significant differences among studied groups of patients in terms of gender $\left(p=0.278\right.$ by $\left.\chi^{2}\right)$ or age ( $p$-value 0.093).The average BMI in all groups was below $30 \mathrm{~kg} / \mathrm{m}^{2}$, the lowest value of BMI was in the group with CC (Tab. 1). There were no significant differences in antidiabetic treatment between the patients with DM without CC and patients with DM and CC.

We observed statistically higher concentration of interleukin-2 in the group of patients with the coexistence of T2DM and CC than in other groups (Tab. 2, Fig. 1).

There was no statistically significant difference in the concentration of interleukin-10 in groups of patients with T2DM with CC compared to subjects with T2DM, with CC or control group (Tab. 2, Fig. 1).

There was no statistically significant difference between the groups in the levels of serum insulin, Cpeptide or HOMA-IR, however higher values of HOMA-IR and insulin levels in the groups with T2DM alone and T2DM with concomitant CC were observed (Tab. 1).

\section{Discussion}

T2DM is often associated with cancer. The risk of CC development among diabetic patients is about 30\% higher than among healthy people. Statistically, there is no significant difference of CC occurrence between women and men with T2DM [3]. There are numerous epidemiological studies which confirm this observation. 
Table 1. Parameters of patients in four groups: Group 1 - patients with T2DM, Group 2 - patients with CC, Group 3 - patients with T2DM and CC, Group 4 - control, people without T2DM and CC

\begin{tabular}{|c|c|c|c|c|c|}
\hline Parameter & Group 1 & Group 2 & Group 3 & Group 4 & p \\
\hline Number of patients & 24 & 24 & 10 & 22 & \\
\hline Female/Male & $16 / 8$ & $12 / 12$ & $6 / 4$ & $17 / 5$ & \\
\hline Average age (years) & 70.63 & 67.50 & 71.50 & 64.73 & 0.093 \\
\hline Age standard deviation & 6.43 & 10.76 & 9.03 & 8.96 & \\
\hline BMI average [kg/m2] & 29.22 & 24.99 & 27.83 & 27.09 & 0.028 \\
\hline BMI standard error & 1.2 & 0.92 & 0.65 & 0.65 & \\
\hline Average fasting insulin [ulU/ml] & 12.81 & 8.91 & 17.09 & 9.01 & 0.2389 \\
\hline Fasting insulin standard error & 3.64 & 1.59 & 4.81 & 1.27 & \\
\hline Average C-peptyd [ng/ml] & 2.95 & 2.41 & 3.38 & 2.39 & 0.373 \\
\hline C-peptyd standard error & 0.51 & 0.29 & 0.53 & 0.18 & \\
\hline Average FPG [mmol/l] & 7.17 & 4.94 & 6.36 & 5.01 & 0.0001 \\
\hline FPG standard error & 0.43 & 0.12 & 0.48 & 0.11 & \\
\hline Average HOMA IR & 4.49 & 1.96 & 4.82 & 1.99 & 0.053 \\
\hline HOMA IR standard error & 1.33 & 0.33 & 1.51 & 0.35 & \\
\hline
\end{tabular}

Table 2. Concentrations of IL-2 and IL-10 in Group 1 (DM), Group 2 (CC), Group 3 (CC and DM), and Group 4 (without CC and DM)

\begin{tabular}{lccccc}
\hline IL-2 & Group 1 & Group 2 & Group 3 & Group 4 & $\mathbf{p}$ \\
\hline Average [pg/ml] & 1.57 & 1.64 & 4.21 & 1.95 & 0.041 \\
SD & 2.07 & 1.22 & 5.08 & 2.04 & \\
SE & 0.44 & 0.27 & 1.61 & 0.47 & \\
Mediana & 1.05 & 1.45 & 3.10 & 1.20 & \\
\hline IL-10 & Group 1 & Group 2 & Group 3 & Group 4 & $\mathbf{p}$ \\
\hline Average $[\mathrm{pg} / \mathrm{ml}]$ & 1.97 & 2.10 & 2.84 & 1.94 & 0.836 \\
SD & 1.72 & 2.55 & 2.98 & 3.27 & \\
SE & 0.37 & 0.57 & 0.99 & 0.75 & \\
Mediana & 1.50 & 1.50 & 2.20 & 0.90 & \\
\hline
\end{tabular}

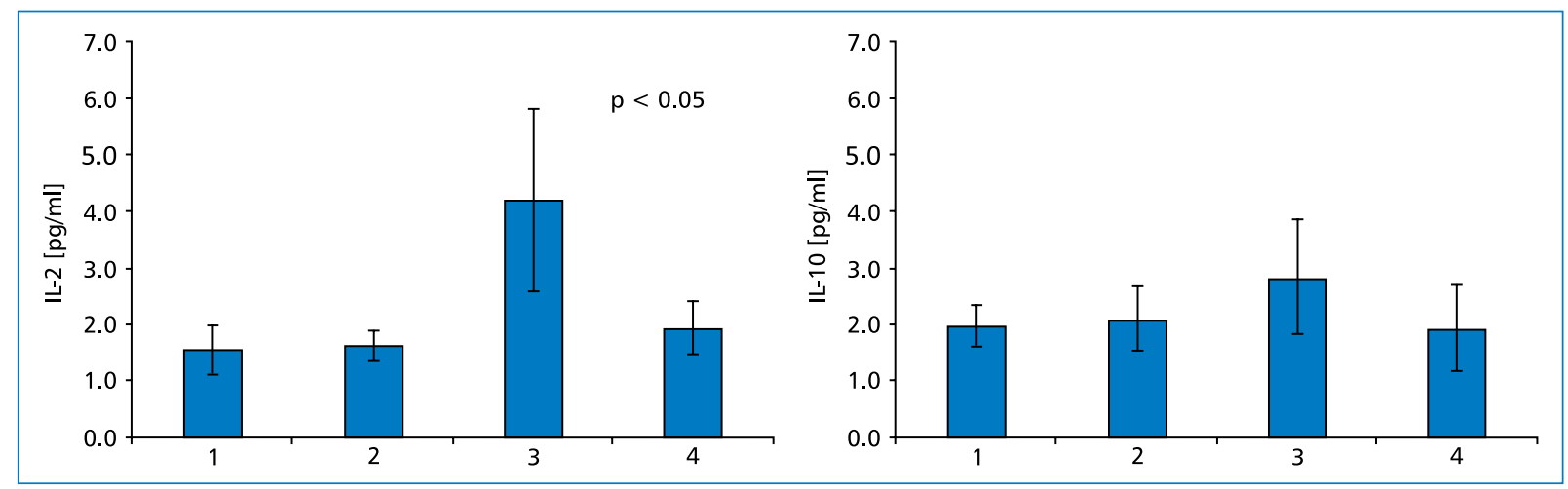

Figure 1. Concentration of IL-2 and IL-10 in Group 1 (DM), Group 2 (CC), Group 3 (CC and DM), and Group 4 (without CC and DM)

Taiwanese research showed a higher risk of development of breast, colon, liver, pancreas and lung cancer in patients with T2DM [23]. The metaanalysis of Yuhara et al. shows that T2DM is an independent risk factor in the development of large intestine and rectal cancer [16]. This dependency does not change after evaluation 
of additional risk factors such as smoking, obesity and a lack of physical exercise. The risk of CC development among T2DM patients was greater than that of rectal cancer. In this research T2DM was related with a higher risk of CC development among both men and women. In terms of rectal cancer this type of relation was noticed only among men [16]

A prospective, multiethnic, cohort research that evaluated over two hundred thousand people (White, Afro-American, Japanese, native Hawaiian and Latino origin), confirmed a higher risk of CC development among patients with diabetes compared to persons without diabetes in all the groups except the native Hawaiian people [5].

On the basis of a metaanalysis of controlled, prospective, multiethnic and cohort researches published after the year 2007 De Bruijn et al. deduced that T2DM was a risk factor of breast and CC and, furthermore, a risk factor of death from these diseases [24].

A few pathogenic mechanisms leading to the development of tumors in patients with T2DM were considered. The effects of hyperglycemia, hyperinsulinemia, and insulin resistance can be responsible for it. A link between obesity, chronic inflammation and impaired immune system was observed [25, 26]. The European Prospective Investigation into Cancer and Nutrition Study (EPIC) showed that elevated levels of C-peptide as a marker of hyperinsulinemia positively correlated with the risk of colon and rectum cancer development. Furthermore, a high level of C-peptide and low level of IGFBP-1 (insulin-like growth factor-binding protein 1) was associated with a higher risk of death after a previous surgery for colon and rectum cancer [27].

Insulin is an anabolic hormone which intensifies lipogenesis, DNA, protein and glycogen synthesis but slows down lipolysis, gluconeogenesis and glycogenolysis. High concentration of insulin exerts mitogenic and anti-apoptotic effects. Insulin stimulates the growth and differentiation of cells. Binding to specific receptors such as IR (insulin receptor), IGF-1R (insulin-like growth factor 1 receptor) and acting through the pathways of MAPK (mitogen-activated protein kinase) and PI3K (phosphoinositide 3-kinase), insulin sends mitogenic signals into the cell nucleus, increases the synthesis of proteins and fatty acids and inhibits apoptosis. In addition, insulin decreases the level of proteins that bind IGF (insulin-like growth factor-binding proteins). It leads to an increased activity of IGF-1. The IGF is an important factor of growth associated with cancerogenesis [16]. Cancer cells have an increased receptor expression for insulin and IGF-1. It leads to escalation of insulin influence on the cancer expansion $[16,28]$.
T2DM is often associated with abdominal obesity, which is linked to insulin resistance and overproduction of pro-inflammatory adipokines. These adipokines stimulate other adipocytes and macrophages of the fat tissue to produce pro-inflammatory factors. Many studies revealed increased serum level of TNF- $\alpha$ (tumor necrosis factor-alpha), interleukin-2, INF- $\gamma$ (interferon gamma), CRP (C-reactive protein) in T2DM [29-31]. The correlation between obesity and the development of a colon tumor may be associated with chronic inflammation [32-34]. Pro-inflammatory cytokines, which are secreted by fatty tissue cells, have a potentially neoplastic effect $[35,36]$.

Such factors as interleukin-2, interleukin-6, interleukin-10, TNF $\alpha$, interferon $\gamma$ adiponectin, leptin, PAI-1 (plasminogen activator inhibitor-1) and MCP-1 (monocyte chemoattractant protein-1) may play an important role in cancer cell transformation or cancer progression [21, 37-43]. Disturbances of cytokines secretion directly or indirectly affect the immune system.

In our study we observed statistically higher concentrations of IL-2 in the group of patients with T2DM and CC $(4.21 \pm 1.61 \mathrm{SE} \mathrm{pg} / \mathrm{ml})$ than in the other groups (group $1-1.57 \pm 0.44 \mathrm{SE} \mathrm{pg} / \mathrm{ml}$, group $2-1.64 \pm$ $0.27 \mathrm{SE} \mathrm{pg} / \mathrm{ml}$, group $4-1.95 \pm 0.47 \mathrm{SE} \mathrm{pg} / \mathrm{ml}$.

IL-2 is produced by Th1 antigen recognizing lymphocytes and in a smaller amount of cytotoxic T lymphocytes and other immunological cells among others NK cells, NKT cells [14].

Expression of IL-2 can be increased more than 1000 times after activation of lymphocytes. IL-2 acts on cells by stimulation of high-affinity trimeric IL-2R or the lowaffinity dimeric IL-2R. The IL-2 receptor comprises three subunits including IL-2R $\alpha$ (CD25), IL-2R $\beta$ (CD122) and IL-2R $\gamma$ (CD132). The dimeric IL-2R is present on memory CD8 + T cells, NK cells, naive CD8+ T cells and memory CD4+ T cells. CD25 is the third chain of the trimeric IL$-2 R$. It increases the affinity of the IL-2R for its ligand by 100 -fold. High levels of the trimeric IL-2R are expressed by CD4+ and CD8 + T cells following TCR (T cell receptor) activation. Treg cells constitutively express high levels of CD25. The expression of CD25 by T cells is regulated by TCR stimulation and by contact with IL-2. Signal transduction of IL-2 includes the Janus kinase (JAK)-STAT pathway, 3-kinase (PI3K)-AKT pathway and the mitogen activated protein kinase (MAPK) pathway $[14,17,44]$.

The main action of IL-2 is augmentation of proliferation and activation of regulatory $\mathrm{T}$ lymphocytes. It may facilitate development of CC. The increased number of Treg lymphocytes in colon tumor was associated with progression of cancer and higher prevalence of metastases $[9,45]$. 
Treg cells participate in the development of tolerance to antigens associated with cancer. It was shown in studies on populations in the Far East that there is an association between activated Treg lymphocytes and progression of CC. Activated Treg lymphocytes in colon cancer tissue were correlated with those in cancer metastasis, and their presence influenced negatively on the cancer immune system of the patients [45].

In the studies conducted by Svensson $\mathrm{H}$, et al. on subpopulations of lymphocytes, which infiltrate a cancer tissue and normal mucosa in patients with CC, it was shown that regulatory $T$ lymphocytes accumulate in the tissues changed by cancer while the activated Th1 lymphocytes are less represented. Changed proportions of the number of different types of lymphocytes in CC probably have an impact on the capabilities of anticancer immune response [9].

IL-2 is also involved in activation of cytotoxic T lymphocytes (Tc lymphocytes). Tc cells destroy cancer cells [46].

IL-2 can act in various way on an immunological state activating or inhibiting the immunological answer. The effect of IL-2 is largely determined by the concentration of IL-2 in the blood. High serum IL-2 level activates CD8 + CD25- cells, which increase the anti-tumor activity. In contrast, chronic persistent elevated IL-2 levels are associated with a predominant influence on activation of Treg lymphocytes. Treg lymphocytes have trimeric receptors. These receptors have a high affinity for this cytokine, compared to CD8 + lymphocytes [17].

The results of our study indicate differences in the immune system of patients with T2DM with the coexistence of CC compared to people without T2DM and without CC. A statistically higher concentration of IL-2 was observed in the group of patients with T2DM and CC than in the groups without diabetes or large intestine cancer. Higher levels of IL-2 can be potentially connected with an increased risk of CC. Elevated concentrations of IL-2 identified in the group of patients with T2DM and CC, when confirmed in other studies on a larger number of patients, could be used as a marker for an increased risk of development of CC in diabetic patients. Our' findings can contribute to a change in procedures in the screening of colon cancer in patients with T2DM.

There were no statistically significant differences in the concentrations of IL-10 in patients with T2DM and CC compared to other subjects in our study.

The major source of IL-10 is CD4+ T cells. IL-10 may be also produced by CD8+ lymphocytes, macrophages, monocytes, dendritic cells and tumor cells. The prerequisite condition of IL-10 secretion by $T$ cells is their activation by antigen presenting cells $[11,19,20]$.

IL-10 receptor complex consists of IL-10 receptor 1 (IL-10R1) and IL-10 receptor 2 (IL-10R2). IL-10R1 binds IL-10 with a high affinity. Most hematopoietic cells express low levels of IL-10R 1 and a receptor expression can be upregulated by various stimuli. The IL-10R2 is expressed on most cells. Binding of IL-10 to the receptor activates among others the Janus tyrosine kinases, JAK1 and Tyk2. It results in the activation of STAT proteins and translocates them into the nucleus. IL-10 activates the STAT1, STAT3, STAT5 pathways. Activation of the STAT pathways may be important for the development of colon cancer. For example, STAT3 activates the suppressor of cytokine signaling 3 (SOCS3). SOCS3 is induced by IL-10 and exerts negative regulatory effects on various cytokine genes $[19,21,47,48]$.

$\mathrm{IL}-10$ treatment results in a diminished nuclear factor $-\kappa \mathrm{B}(\mathrm{NF}-\kappa \mathrm{B})$ activation. IL-10 may also inhibit $N F-\kappa B$ translocation into the nucleus. The inhibition of NF- $\kappa$ B by IL-10 prevents DC maturation and diminishes the function of antigen-presenting cells (APCS). IL-10 exerts effect on APCs to prevent the production of IL-2 and interferon-gamma. IL-10, on the one hand, inhibits responses to alloantigens, on the other hand, contributes to the reduction of IL-2 production. IL-2, in turn, stimulates Treg lymphocytes, which participate in the development of tolerance to antigens associated with cancer $[11,20]$.

IL-10 inhibits the production of IL-1, IL-6, IL-12, and tumor necrosis factor (TNF). IL-10 activates natural killer (NK) cell proliferation. The progression of CC may be associated with the change in cytokine production by Treg cells from IL-10 to IL-17, which promotes tumor development. The treatment with antibodies against IL-10 can be effective in the case of neoplastic diseases $[11,19,48]$. IL-10 has a multidirectional influence on immunological state.

In our study the lack of differences in serum concentration of IL-10 in the groups of patients with colon cancer may be associated with the complex role of IL-10 in the development and progression of CC. The concentrations of serum insulin, C-peptide and HOMA-IR do not significantly differ among the groups, although higher values of HOMA-IR and insulin levels were observed in the groups with T2DM and T2DM associated with CC.

Wider recognition of the risk factors for CC as well as differences in immunological state in individuals with the coexistence of T2DM can become the basis for a strategy in the prevention of colon cancer and may help in the selection of groups of patients with T2DM, prone to the development of colon cancer. 


\section{Conclusions}

The concentration of IL-2 was statistically higher in the group of patients with T2DM and CC than in the groups of patients without those diseases. The coexistence of T2DM and CC is characterized by an increased level of serum IL-2.

IL-2 can potentially have an influence on the development of cancer and progress of malignancy. An elevated level of IL-2 may be a marker of an increased risk of CC in patients with T2DM. It is recommended to carry out tests on a larger group of patients. It could be useful to select the group of patients with differences in immune system particularly susceptible to the development of CC. It seems that patients with T2DM and the increased level of IL-2 should be taken into a special oncological care.

The lack of differences of IL-10 serum levels between the groups with and without colon cancer may be associated with multidirectional effects of this cytokine.

\section{Ethics approval and consent to participate}

This study was approved by the local Research Ethics Committee and was conducted in accordance with the Declaration of Helsinki and a written consents were obtained from all the participants.

\section{Authors' contributions}

IB contributed to the design of the study, data collection and data analysis and was involved in editing the final version of the manuscript; RK contributed to data collection and data analysis and was involved in editing the final version of the manuscript; $\mathrm{BK}$ and $\mathrm{MK}$ were involved in laboratory tests; TM was involved in data collection and data analysis; MR was involved in editing the final version of the manuscript; PC contributed to the design of the study; PP conceived the idea for the study and contributed to the design of the research.

All authors read and approved the final manuscript.

\section{Availability of data and materials'}

The data sets used and/or analyzed during the current study are available from the corresponding authors on request.

\section{Competing interests}

The authors declare that they have no competing interests.

The study was supported by the grant No NN402356938.

\section{REFERENCES}

1. International Agency for Research on Cancer: GLOBOCAN 2012: Estimated Cancer Incidence, Mortality and Prevalence Worldwide in 2012. Lyon, International Agency for Research on Cancer 2014.

2. Bray F, Jemal A, Grey N, et al. Global cancer transitions according to the Human Development Index (2008-2030): a populationbased study. Lancet Oncol. 2012; 13(8): 790-801, doi: 10.1016/ /S1470-2045(12)70211-5, indexed in Pubmed: 22658655.

3. Larsson SC, Orsini N, Wolk A. Diabetes mellitus and risk of colorectal cancer: a meta-analysis. J Natl Cancer Inst. 2005; 97(22): 1679-1687, doi: 10.1093/jnci/dji375, indexed in Pubmed: 16288121

4. González N, Prieto I, Del Puerto-Nevado L, et al. DiabetesCancerConnect Consortium. 2017 update on the relationship between diabetes and colorectal cancer: epidemiology, potential molecular mechanisms and therapeutic implications. Oncotarget. 2017; 8(11): 18456-18485, doi: 10.18632/oncotarget.14472, indexed in Pubmed: 28060743.

5. He J, Stram DO, Kolonel LN, et al. The association of diabetes with colorectal cancer risk: the Multiethnic Cohort. Br J Cancer. 2010; 103(1): 120-126, doi: 10.1038/sj.bjc.6605721, indexed in Pubmed: 20531412.

6. Rutkowski M, Bandosz P, Czupryniak L, et al. Prevalence of diabetes and impaired fasting glucose in Poland - the NATPOL 2011 Study. Diabet Med. 2014; 31(12): 1568-1571, doi: 10.1111/ /dme.12542, indexed in Pubmed: 24975751.

7. Li Y, Wang L, Pappan L, et al. IL- $1 \beta$ promotes stemness and invasiveness of colon cancer cells through Zeb1 activation. Mol Cancer. 2012; 11: 87, doi: 10.1186/1476-4598-11-87, indexed in Pubmed: 23174018.

8. Lin YC, Mahalingam J, Chiang JM, et al. Activated but not resting regulatory $T$ cells accumulated in tumor microenvironment and correlated with tumor progression in patients with colorectal cancer. Int J Cancer. 2013; 132(6): 1341-1350, doi: 10.1002/ /ijc.27784, indexed in Pubmed: 22907255.

9. Svensson $H$, Olofsson $V$, Lundin $S$, et al. Accumulation of $\mathrm{CCR}^{+}{ }^{+} \mathrm{CTLA}-4 \mathrm{FOXP}^{+}{ }^{+} \mathrm{CD} 25$ (hi) regulatory $\mathrm{T}$ cells in colon adenocarcinomas correlate to reduced activation of conventional T cells. PLoS One. 2012; 7(2): e30695, doi: 10.1371/journal. pone.0030695, indexed in Pubmed: 22319577.

10. Waldner MJ, Foersch S, Neurath MF. Interleukin-6 - a key regulator of colorectal cancer development. Int J Biol Sci. 2012; 8(9): 1248-1253, doi: 10.7150/ijbs.4614, indexed in Pubmed: 23136553.

11. Ng TH, Britton GJ, Hill EV, et al. Regulation of adaptive immunity; the role of interleukin-10. Front Immunol. 2013; 4: 129, doi: 10.3389/fimmu.2013.00129, indexed in Pubmed: 23755052.

12. Wu D, Wu P, Huang Qi, et al. Interleukin-17: a promoter in colorectal cancer progression. Clin Dev Immunol. 2013; 2013: 436307, doi: 10.1155/2013/436307, indexed in Pubmed: 24382972.

13. Zhang J, Mao T, Wang S, et al. Interleukin-35 expression is associated with colon cancer progression. Oncotarget. 2017; 8(42): 71563-71573, doi: 10.18632/oncotarget.17751, indexed in Pubmed: 29069729.

14. Malek TR. The biology of interleukin-2. Annu Rev Immunol. 2008; 26: 453-479, doi: 10.1146/annurev.immunol.26.021607.090357, indexed in Pubmed: 18062768.

15. Francisco CO, Catai AM, Moura-Tonello SCG, et al. Cytokine profile and lymphocyte subsets in type 2 diabetes. Braz J Med Biol Res. 2016; 49(4): e5062, doi: 10.1590/1414-431X20155062, indexed in Pubmed: 27007651.

16. Yuhara $H$, Steinmaus $C$, Cohen $S E$, et al. Is diabetes mellitus an independent risk factor for colon cancer and rectal cancer? Am J Gastroenterol. 2011; 106(11): 1911-1921; quiz 1922, doi: 10.1038/ajg.2011.301, indexed in Pubmed: 21912438. 
17. Boyman O, Sprent J. The role of interleukin-2 during homeostasis and activation of the immune system. Nat Rev Immunol. 2012; 12(3): 180-190, doi: 10.1038/nri3156, indexed in Pubmed: 22343569.

18. Mannino $\mathrm{MH}$, Zhu Z, Xiao $\mathrm{H}$, et al. The paradoxical role of IL-10 in immunity and cancer. Cancer Lett. 2015; 367(2): 103-107, doi: 10.1016/j.canlet.2015.07.009, indexed in Pubmed: 26188281.

19. Mosser DM, Zhang $X$. Interleukin-10: new perspectives on an old cytokine. Immunol Rev. 2008; 226: 205-218, doi: 10.1111/j.1600065X.2008.00706.x, indexed in Pubmed: 19161426.

20. Saraiva M, O'Garra A. The regulation of IL-10 production by immune cells. Nat Rev Immunol. 2010; 10(3): 170-181, doi: 10.1038/ /nri2711, indexed in Pubmed: 20154735.

21. Mager LF, Wasmer MH, Rau TT, et al. Cytokine-Induced Modulation of Colorectal Cancer. Front Oncol. 2016; 6: 96, doi: 10.3389/ /fonc. 2016.00096, indexed in Pubmed: 27148488.

22. Sato T, Terai M, Tamura $Y$, et al. Interleukin 10 in the tumor microenvironment: a target for anticancer immunotherapy. Immunol Res. 2011; 51(2-3): 170-182, doi: 10.1007/s12026-011-8262-6, indexed in Pubmed: 22139852.

23. Hsieh MC, Lee TC, Cheng SM, et al. The influence of type 2 diabetes and glucose-lowering therapies on cancer risk in the Taiwanese. Exp Diabetes Res. 2012; 2012: 413782, doi: 10.1155/2012/413782, indexed in Pubmed: 22719752.

24. De Bruijn KMJ, Arends LR, Hansen BE, et al. Systematic review and meta-analysis of the association between diabetes mellitus and incidence and mortality in breast and colorectal cancer. $\mathrm{Br} \mathrm{J}$ Surg. 2013; 100(11): 1421-1429, doi: 10.1002/bjs.9229, indexed in Pubmed: 24037561.

25. Giovaucci E. Metabolic syndrome, hiperinsulinemia and colon cancer: a review. Am J Clin Nutr. 2007; 86(3): 836-842.

26. Piątkiewicz P, Czech A. Glucose metabolism disorders and the risk of cancer. Arch Immunol Ther Exp (Warsz). 2011; 59(3): 215-230, doi: 10.1007/s00005-011-0119-0, indexed in Pubmed: 21448680.

27. Jenab M, Riboli E, Cleveland RJ, et al. Serum C-peptide, IGFBP-1 and IGFBP-2 and risk of colon and rectal cancers in the European Prospective Investigation into Cancer and Nutrition. Int J Cancer. 2007; 121(2): 368-376, doi: 10.1002/ijc.22697, indexed in Pubmed: 17372899.

28. Holden SE. Diabetes and Cancer. Endocr Dev. 2016; 31: 135-145, doi: 10.1159/000439410, indexed in Pubmed: 26824829.

29. Brunner EJ, Kivimäki M, Witte DR, et al. Inflammation, insulin resistance, and diabetes - Mendelian randomization using CRP haplotypes points upstream. PLoS Med. 2008; 5(8): e155, doi: 10.1371/journal.pmed.0050155, indexed in Pubmed: 18700811.

30. Yaturu S, Rains J, Jain SK. Relationship of elevated osteoprotegerin with insulin resistance, CRP, and TNF-alpha levels in men with type 2 diabetes. Cytokine. 2008; 44(1): 168-171, doi: 10.1016/j. cyto.2008.07.471, indexed in Pubmed: 18789716.

31. Schloot NC, Hanifi-Moghaddam P, Goebel C, et al. Serum IFNgamma and IL-10 levels are associated with disease progression in non-obese diabetic mice. Diabetes Metab Res Rev. 2002; 18(1): 64-70, doi: 10.1002/dmrr.256, indexed in Pubmed: 11921420.

32. Kim S, Keku TO, Martin C, et al. Circulating levels of inflammatory cytokines and risk of colorectal adenomas. Cancer Res. 2008; 68(1): 323-328, doi: 10.1158/0008-5472.CAN-07-2924, indexed in Pubmed: 18172326.

33. Sasaki Yu, Takeda H, Sato T, et al. Serum Interleukin-6, insulin, and HOMA-IR in male individuals with colorectal adenoma. Clin Cancer Res. 2012; 18(2): 392-399, doi: 10.1158/1078-0432.CCR11-0896, indexed in Pubmed: 22048241.
34. Day SD, Enos RT, McClellan JL, et al. Linking inflammation to tumorigenesis in a mouse model of high-fat-diet-enhanced colon cancer. Cytokine. 2013; 64(1): 454-462, doi: 10.1016/j. cyto.2013.04.031, indexed in Pubmed: 23735174.

35. Zhu M, Zhu Y, Lance P. TNF $\alpha$-activated stromal COX-2 signalling promotes proliferative and invasive potential of colon cancer epithelial cells. Cell Prolif. 2013; 46(4): 374-381, doi: 10.1111/ /cpr.12047, indexed in Pubmed: 23869759.

36. Putoczki TL, Thiem S, Loving A, et al. Interleukin-11 is the dominant IL-6 family cytokine during gastrointestinal tumorigenesis and can be targeted therapeutically. Cancer Cell. 2013; 24(2): 257-271, doi: 10.1016/j.ccr.2013.06.017, indexed in Pubmed: 23948300.

37. Prieto-Hontoria PL, Pérez-Matute $P$, Fernández-Galilea $M$, et al. Role of obesity-associated dysfunctional adipose tissue in cancer: a molecular nutrition approach. Biochim Biophys Acta. 2011; 1807(6): 664-678, doi: 10.1016/j.bbabio.2010.11.004, indexed in Pubmed: 21111705.

38. Gallagher EJ, LeRoith D. Obesity and Diabetes: The Increased Risk of Cancer and Cancer-Related Mortality. Physiol Rev. 2015; 95(3): 727-748, doi: 10.1152/physrev.00030.2014, indexed in Pubmed: 26084689.

39. Marszałek A, Szylberg L, Wiśniewska E, et al. Impact of COX-2, $\mathrm{IL}-1 \beta$, TNF- $\alpha, \mathrm{IL}-4$ and IL-10 on the process of carcinogenesis in the large bowel. Pol J Pathol. 2012; 63(4): 221-227, doi: 10.5114/ /pjp.2012.32768, indexed in Pubmed: 23359190.

40. Setia S, Nehru B, Sanyal SN. Activation of NF- $\kappa$ B: bridging the gap between inflammation and cancer in colitis-mediated colon carcinogenesis. Biomed Pharmacother. 2014; 68(1): 119-128, doi: 10.1016/j.biopha.2013.09.003, indexed in Pubmed: 24269000.

41. Klampfer L. Cytokines, Inflammation and Colon Cancer. Current Cancer Drug Targets. 2011; 11(4): 451-464, doi: 10.2174/1568 00911795538066.

42. Kalvakolanu DV. Cytokine signaling in cancer: Novel players and pathways. Cytokine. 2017; 89: 1-3, doi: 10.1016/j. cyto.2016.11.012, indexed in Pubmed: 27894807.

43. Abtahi S, Davani F, Mojtahedi Z, et al. Dual association of serum interleukin-10 levels with colorectal cancer. J Cancer Res Ther. 2017; 13(2): 252-256, doi: 10.4103/0973-1482.199448, indexed in Pubmed: 28643743.

44. Malek TR, Castro I. Interleukin-2 receptor signaling: at the interface between tolerance and immunity. Immunity. 2010; 33(2): 153-165, doi: 10.1016/j.immuni.2010.08.004, indexed in Pubmed: 20732639.

45. Lin YC, Mahalingam J, Chiang JM, et al. Activated but not resting regulatory $T$ cells accumulated in tumor microenvironment and correlated with tumor progression in patients with colorectal cancer. Int J Cancer. 2013; 132(6): 1341-1350, doi: 10.1002/ /ijc.27784, indexed in Pubmed: 22907255.

46. Kang $\mathrm{T}$, Mao $\mathrm{CP}, \mathrm{He} \mathrm{L}$, et al. Tumor-targeted delivery of IL-2 by NKG2D leads to accumulation of antigen-specific CD8+ T cells in the tumor loci and enhanced anti-tumor effects. PLoS ONE. 2012; 7(4): e35141, doi: 10.1371/journal.pone.0035141.

47. Djaldetti $\mathrm{M}$, Bessler $\mathrm{H}$. Modulators affecting the immune dialogue between human immune and colon cancer cells. World J Gastrointest Oncol. 2014; 6(5): 129-138, doi: 10.4251/wjgo.v6.i5.129, indexed in Pubmed: 24834143.

48. Commins S, Steinke JW, Borish L. The extended IL-10 superfamily: IL-10, IL-19, IL-20, IL-22, IL-24, IL-26, IL-28, and IL-29. J Allergy Clin Immunol. 2008; 121(5): 1108-1111, doi: 10.1016/j. jaci.2008.02.026, indexed in Pubmed: 18405958 